\title{
Towards a Usability Coaching Method for Institutionalizing Usability in Organisations
}

\author{
Åsa Cajander ${ }^{1}$, Elina Eriksson ${ }^{2}$, and Jan Gulliksen ${ }^{2}$ \\ ${ }^{1}$ Uppsala university, Dept. Of IT/HCI, PO Box 337, \\ 75105 Uppsala, Sweden \\ ${ }^{2}$ KTH (Royal Institute of Technology) \\ 10044 Stockholm, Sweden \\ Asa.Cajander@it.uu.se, elina@kth.se, gulliksen@csc.kth.se
}

\begin{abstract}
The ideas related to user centred systems design are difficult to implement in organisations and usability is given low priority in in-house systems development. This problem is multifaceted and complex and needs to be addressed with a method capable of adapting to situations, people and context. In this paper we outline a new method - usability coaching - that has the capability for dealing with the situated problems of introducing user centred systems development in an organisations. The method is the results of a larger action research case study in which 9 individuals in an organization received usability coaching. Our study indicates that the coaching program made coachees work more actively with usability activities; hence the coaching program had a substantial effect on their actions and contributed to the organizational change.
\end{abstract}

Keywords: Coaching, user centred-systems design, organizational change, usability, action research, qualitative research, learning theories, conceptual change, and threshold concept.

\section{Introduction}

"Usability and user centred systems design is like peace in the world. Everyone says that it is truly important, but no one really understands how they can contribute to it, and no one takes responsibility for it". This colorful quote from an experienced project manager in a large government organisation captures the difficulties achieving user centered systems design (UCSD), [1]. Our research group has extensive experiences from action research projects in close cooperation with large government organizations with the goal of contributing to a good work environment by promoting UCSD [2]. Previous research has shown that it is not sufficient to work with the systems development department in an organization - attitudes on all levels in the organization need to change $[1,2]$.

The following story about an IT manager illustrates how we have addressed this issue trough a new usability method that we call "Usability Coaching" and we will subsequently analyze different aspects of this story: John is a 50-year-old very experienced top level IT manager in a government organisation. He had prior to the usability coaching not paid much attention to UCSD aspects in development projects. However, he was very dedicated to the 
coaching program, where he took every opportunity to discuss usability and usability issues in relation to his daily work and his responsibilities.

During one of the first coaching sessions there was a discussion concerning the waterfall model in relation to iterative design where John saw no reason to work iteratively in their systems development projects. Among other things, he expressed that "Iterative design is relevant in companies that work with new product development. But business development through IT requires a waterfall model." We had an animated discussion, and John expressed a variety of reasons for not working iteratively. Many, but not all, of these had been voiced by him in an earlier workshop. A few weeks later we were invited to a workshop on usability work in the organisation. John presented a new software development model as a speaker at the workshop. It turned out that the new model he presented was iterative, and included several usability activities.

Our previous research has focused on understanding how to integrate usability in design and especially how basic values and business values affect this integration [3]. Our research indicates that strong business values such as automation, efficiency and customer satisfaction shape the development of new computer systems and ultimately work practices. Moreover, our previous research on manager's and their perspective on usability in the same organization has shown that even though formal usability training has been provided, and despite the organisations official focus on usability managers in the organisation had only vague ideas about what usability is and their responsibility for integrating usability [4]. Most managers agreed that usability was something important in the organization, but they still expressed that they had limited responsibility for usability. Hence one can conclude that most of the managers agreed that usability is important, but that it is someone else's responsibility. Moreover, new methods are needed to impact values and the interpretation of what systems development is about, as well as what goals to strive for in an organisation. The discussion and interest in values and perspectives in systems development is not new in HCI, and the conflict between different perspectives has been extensively discussed, see for example [5-10]. Our research group has worked with informal coaching of professionals to impact values and promoting usability issues. This paper concludes these experiences into an outline of a more formal method for usability coaching. As a basis for this method one of the authors of the paper was enrolled as an external usability coach in a public authority with the dual aims of developing the usability coaching method and to understand how such a method affect the coachees and their actions to promote UCSD in the organisation. The experiences from this case study are discussed in relation to relevant learning theories.

\section{Methodology and Method}

The overarching methodology of this study is action research. This approach is "unique in the way it associates research and practice, so research informs practice and practice informs research synergistically" [11]. Hence, action research has dual aims and is intended to produce both action (change) and research (understanding) [12]. Action research is a participatory research methodology where researchers and practitioners work closely together. The research in this study has been planned and conducted together with participants from the organisation, with a project group within the organisation as the main collaboration partners. The research findings 
described in the case study are based primarily on participatory observations both during the coaching sessions and outside when working together in the project. One of the authors has been the coach in the usability coaching program. During the coaching sessions a handwritten diary was used by the researcher, with focus on the problems discussed. In between the coaching sessions a computer based research diary was used which contained more of a summary of the conversation including didactic and pedagogic notes on how the coaching sessions could have been improved to create a better learning environment. Moreover observations of behaviour by other researchers participating in the research project were also written down in the research diary. Furthermore an interview study was made as an evaluation of the effects of the entire action research project in the organisation. The interview study encompassed 36 semi-structured interviews and is described in more detail in [13]. However, in this article, only those interviews with relevance to the coaching sessions, that is the nine coachees, were analyzed. All interviews were audio recorded and notes were taken, which both were used in the analysis.

Analysis of data from the case study has been done through mind map sessions, where the research diary as well as other written material has supported memory recall. The interviews have been analyzed in two steps, first an analysis where general findings were reported in [13] and then a second analysis with particular focus on the coaching sessions. The notes taken from the interviews were used in order to see emerging themes and where necessary the recorded interviews have been carefully listened through a second time. All quotes in this paper are translated from Swedish and in some cases altered for readability reasons; furthermore, all names have been altered. Halfway through the usability coaching program some preliminary findings was presented and discussed at an INTERACT 2007 workshop [14]. The comments and reviews of that paper have contributed to the subsequent coaching work and also to this paper.

\section{Research on Coaching}

Coaching and mentoring have a very long history and some say that it origins in ancient Greece with links to the Socratic dialogue [15]. Recent studies on the discourses related to mentoring and coaching concludes that the meanings of the words have subtly altered over time and that they have become more or less interchangeable in the modern usage of the word [15]. The purpose of coaching historically has been to help a younger and less experienced person to master a profession or situation through discussions and reflections with a more experienced and older person. This still remains one of the core purposes of many coaching programs today. Despite the lack of a common (well established) definition [16], most researchers agree that the word coach generally indicates a person acting in a supportive relationship as mentor, teacher, leader or role model of some kind. There are some articles on coaching in the HCI area (see for example [17], but it seems to be rather unexplored. The article above describes mentors in en experimental course in HCI. There is however a large body of research on coaching in other research areas such as education, gender research, management theory and organisational theory. An extensive literature review made in 2003 [19] has studied mentoring research from many perspectives. Among 
other things they have looked at studies of mentoring outcomes, and conclude that most studies have focused on outcomes for protégés, rather than on outcomes for coaches or organisations. However, Zey has discussed possible organizational outcomes and identified seven outcomes of mentoring. These organizational outcomes include employee integration, reduction of turnover, organizational communication, management development, managerial succession, productivity and socialization to power. Moreover, there has been quite a few mentoring studies related to how personality traits are related to behaviours in a mentoring relationship [19]. Some of the hypothesis examined are if the drive to excel will lead those with type A personality to have a mentoring relationship [20], or if people with an internal locus of control are more likely to perceive that they can improve their skills [21]. Furthermore, there has been research on how mentoring relationships evolve over time [22] and how the coach and the coachee interact and influence each other. However, despite the fact that mentoring involves intense and interpersonal relationship, research on the how behaviour, perceptions and affect is limited [19].

\section{Learning in a Coaching Situation}

Usability coaching is based on constructivism as the underlying epistemology, i.e. there is no objective truth and that meaning is constructed in interaction between human beings and the world. This perspective implies that the usability coaching program did not work to establish pre-determined ideas where procedures are well defined for situations, or where there is a "right" or objective answer. However, the discussions have been inspired by the values and perspectives of UCSD. Moreover, we agree with Schön [23] that problems can be of different natures and that many problems that occur when trying to introduce new ideas and values such as UCSD in systems development are complex and multifaceted. This is also discussed in general by for example [24] who call these problems "wicked problems". Schön describes these as belonging to the swampy lowland where predefined methods and techniques are of no use when trying to solve the problem. Schön takes this one step further and elaborates on how to educate people in addressing these complex and swampy problems to become reflective practitioners. The usability coaching method can help coachees to reflect on the particular problems of their swampy lowland. Hence the usability coaching we in this paper refers to the learning that Schön describes.

\section{Case Study Setting and the Usability Coaching Program}

The usability coaching was conducted within a large action research project together with the Swedish public authority that handles financial aids for students, CSN. The computer support are mainly developed in-house at headquarters, at the IT-division. The action research project were initiated at the Human Resource department [25]. The goal of the action research project was to increase knowledge about usability and a good computerized work environment.

The usability coaching program was initiated by the project manager at the Human Resource Department and one of the authors of this paper acted as a usability coach. 
The coach was externally financed coach, and the coaching was on a voluntary basis as the coachee had the possibility not to participate in the program. Unlike many coaching programs that have personal competence and career as the focus - the usability coaching program had the aim of institutionalizing usability and UCSD through personal knowledge in the organisation. Hence this usability coaching program aimed at organisational change, and not merely personal knowledge. This usability coaching program was aligned with the long-term objectives and strategic positioning of the organisation as it aims at being the most user-centred authority in Sweden and usability is a part of the business goals of the authority. Another major difference from many other coaching programs is the relation between the coach and the coachee. The coach was only more experienced, being an expert, in one aspect of the profession, i.e. usability. For example, in this usability coaching program the coach is no expert of IT strategies and the strategic work in an authority which was the responsibility of one of the coachees - rather the coach and the coachee create a new understanding of IT strategy work and usability based on their previous experiences and knowledge. Nine key persons representing the main stakeholders in the systems development process were appointed by the organisation, and they had formal titles such as "IT Strategy Manager", "Business Process Manager" and "Human Resource Manager". Seven of the stakeholders also had the role of sub-projectmanagers in the project. All stakeholders had the same coach, and a possibility to meet with the coach every three weeks during one year. Some chose to meet the coach more seldom. The practical goal of the usability coaching program was to encourage people to reflect on their work and behaviour and to achieve a personal accountability of usability issues in the coachee and to influence the organisation to work with usability on all levels. During the coaching sessions the discussions included for example problems and conflicts when introducing the ideas and perspectives of UCSD. Some of these perspectives included views of humans, work, and efficiency as well as automation of services in relation to creating a good work environment. Some coaching sessions concerned the use of different usability methods, but these were rare.

In a retrospective reflection the project manager explained the reasons for launching the usability coaching program in this way: "We had already much increased the level of knowledge, and now there was a need for more continuous usability coaching discussions. I thought the timing was good, and we needed a new approach." Furthermore, during the same interview she presented her expectations of the usability coaching program in the following way: "The expectation I had was that the subproject managers would work harder. That they would get some support in making this change."

\section{Experiences from the Case Study}

Following we will describe and discuss our experiences doing usability coaching. Furthermore it will be related to learning theories and other research in the analysis.

During the final interviews of the project most of the coachees expressed that they had not gained any use of the coaching sessions or that they did not understand the purpose of the coaching sessions. This can be linked to their expectations of the 
coaching sessions, which might have been somewhat different than the expectations of the coach and the project manager who initiated the usability coaching program. It can also be linked to the difficulty of reflecting on changes. Moreover, one can note that a few of the people engaged in the mentoring program were not interested in having a mentor. One reasons for this was that they experienced that they already knew all they need to know about usability and their work.

The action research project was in its last year when the usability coaching program was initiated and the situation and the roles were more stabilized than in the beginning of the project. We believe that if the usability coaching program had started earlier, perhaps even in the very beginning of the project, the benefit of the sessions would have been more apparent to the coachees. This is also something that they themselves express in the interviews, that they believe the program would have been more beneficial in the beginning of the project. However, we have seen in the coaching sessions as well as outside the sessions that the coachees have changed their behavior, John, described below, is one example. These changes are subtle and stretched over time, and in hindsight perhaps difficult to see.

\section{Conceptual Changes and Threshold Concepts}

Conceptual Change [29, 30] and Threshold Concepts [31] are learning theories relevant to the usability coaching situation. That is, consciously intending to create a discussion that exposes the coachee to challenges of their own conceptual views and where they will meet new ideas requiring overcoming of threshold concepts. Conceptual change as described by Entwistle is used in order to understand the learning of the coachee $[30,32]$.

Threshold concepts are much discussed in literature on learning and teaching. Concepts can be seen as building blocks of a discipline, and the threshold concepts are among these building blocks. The threshold concepts in this setting are unique from other concept in the way that they are transformative as they change the way the coachees look at their work. They are also integrative and tie concepts together in new ways and irreversible in that they are difficult to unlearn. However, they might also be troublesome for the coachee as they are perceived as alien, difficult or counter-intuitive. Finally these threshold concepts are often boundary markers as they can be seen as indicating the limits of the conceptual area [33].

In the coaching context, the significance of the framework provided by threshold concepts lies in its explanatory potential to locate troublesome aspects when integrating usability in the organisation. It is principally an analytical framework for trying to understand how coachees learn, where the barriers to their learning lie and how they can be helped to overcome the difficulties. We have come across a few threshold concepts during the coaching sessions. One of the most visible is that IT-systems development creates new work and is responsible for a future good work environment is a concept that many coachees have understood. The results from the study suggests that some coachees have come to recognise that their influence goes beyond making computer systems; they are also influencing and creating the future work environment and health of those who will work with the system. Another threshold concept is that models of systems development are not used as step-to-step procedural descriptions of how to work in a systems development project. Systems development is a complex 
activity, and it consists of many situated decisions and problems that are impossible to solve with the help of prevailing standards or methods. Work is situated, and models of work cannot capture this aspect of work. Finally, we have identified that iterative systems development as a concept seems to be a threshold concept difficult to incorporate and to fully understand. Many of the coachees expressed that it is impossible to work iteratively due to reasons such as the test environment, the project management methods and the business plan for the authority.

The most important finding from this study is the power of impact the usability coaching program has had on many of the coachees, and on their way of talking about usability and taking responsibility for usability issues in their professional role. This could be seen from their behaviour in other contexts where usability was mentioned. From the theories of conceptual change this can be seen as if they have transformed through their new understandings through discovering, applying and assimilating new knowledge. The discussions with John have made him consider and reconsider the way systems development and architecture of IT is organised, and he questions and discusses many aspect of usability work in relation to his work. One example is a discussion about usability aspects when automating case handling in the spirit of e-Government. John believes that from an automation point of view, the user is irrelevant and that the goal of automation in the organisation is contradictory to the goal of usable computer systems and a good work environment. Here John identified two contradictory perspectives on work within the organisation, and had difficulties in understanding how to move forward in his work with this new knowledge:

"If the automation is our focus, then our focus isn't on the user and how he is supported by the system. And that becomes contradictory, I think. And from this perspective the user is irrelevant, if you know what I mean".

\section{Personal Conflicts}

During the coaching sessions many coachees described conflicts and discussions they had with other people and/or departments of the organisation. Also in the interviews, conflicts were mentioned and one of the perceived benefits of the coaching program as a good and constructive environment to discuss the handling of personal conflicts and dilemmas. Some of the conflicts were highly relevant for the project goals for example difficulties in communication with people or departments, and critical statements and rumours about the achievements of the project which resulted in discussions and conflicts. Other examples were that personal conflicts between people in the organisation made it impossible for some parts of the organisation to cooperate. The handling of the discussion around these conflicts was indeed a core part of the coaching sessions, which might seem quite surprising given that the coaching focused on usability and related activities to the introduction of the ideas behind UCSD.

These results concur with recent research in HCI [34] that describes usability work as a human activity where for example learning, personality, conflicts are illuminated. When working with the introduction of new ideas and perspectives conflicts are likely to occur as people change their work and view of the responsibilities in the organisation when collaborating. Nørgaard describes the problems of cross professional collaboration in the following way: "Our work shows that cross-professional 
collaboration is subject to challenges that arise from stakeholders having conflicting priorities, procedures and personalities." The amount of conflicts can also be seen as a result of the organisational change that the project aimed for. During a change process there are often frustrating feelings when people try to understand and make sense of the new organisation.

\section{Private vs. Official}

One of the most difficult problems with usability coaching is to decide what parts of the sessions that are private, and what parts are official. In many of the usability coaching sessions the coach and the coachee tended to discuss conflicts and personal experiences working with others. Some of these discussions have true relevance to the success of the usability project, and if discussed openly the possibilities for the project to succeed would improve. Examples of such conflicts are conflicts between the usability professionals and different units in the organisation.

A discussion about the consequences of considering the coaching sessions as private or official is appropriate. If the coaching sessions are considered as private this might imply that the coachee feels free to express opinions and perspectives in a more open manner. John expresses his view of the coaching session in the following way: "Coaching is a relationship with high integrity; it's a thing between you and me." However, later on in the interview he also talks about how beneficial the coaching sessions could be in helping him handling conflicts with others. That the coach can see the difference in expectations that different people have and give advice on how to handle this. This suggests that some of the discussions during the coaching sessions are very relevant to other coachees as they might describe interpretations of situations and conflicts that explain why difficulties arise. The question of confidentiality is explored in literature on coaching [15] where confidentiality is seen as fundamental for the success of coaching.

\section{Usability Coaching - Towards a More Formal Method}

As a conclusion of the experience of this case and of previous coaching experiences we want to specify the usability coaching method as a way to capture and disseminate the insights and knowledge we gained during the cases. Our understanding of the usability coaching method is inspired by Schön's [35] view of reflection-in-action: most real life situations are confusing messes where the problem has to be understood and the solution to the problem must be defined according to the person's personal, tacit experience rather than to any abstract general knowledge. Hence a description of the usability coaching method should not work as a normative guide that describes how a problem should be solved. Rather, we believe that a method seen from this reflection-on-action approach can be useful in a number of ways, for example as a common language and description of what to aim for in the coaching situation. In this study the word coach was chosen since it was what the organisation used when talking about the program. Moreover, the following definition is used to describe the usability coaching situation: 
Usability coaching is a method that, based on the basic values of usability and $U C S D$, supports people in reflecting on their views and actions and on their role for promoting usability in the organisation and in any ongoing development activities.

\section{Preparation}

When preparing the mentoring program the coach needs to discuss the expectations and goals of the program. The organisation and the coachee might have slightly different goals, but there must be a main theme. The goals and the expectations are best discussed in meetings where the frame of the coach program is set up. Moreover, practical matters such as time, length and duration should be set. Other issues that need to be addressed are the accessibility of the coach. Is it OK for the coachee to mail and call in-between meetings? How much time should the coach spend reading, commenting or reflecting on reports, strategy plans, design, methods etc in-between meetings? When preparing the coaching sessions it is a good idea to have a general picture of the organisation and the organisational goals to understand the context of the coaching session. Field studies or an interview study is recommended in order to get this knowledge. Furthermore we also recommend that the coach keeps a diary with relevant information and has a plan of how to organize the information gained. The aim of the diary is memory recall and a way to remember things to look up or learn more about between meetings. Either the coach has one diary for all coach sessions, or separate diaries for each person. To support the goal of increased awareness of usability and UCSD we believe that the coach needs to be a senior usability professional with practical experience from working with usability methods and with an education in HCI subjects. In discussions the coach needs to be a good listener who is interested in understanding the coachee and his/her work situation. Preferable personality traits according to descriptive research in coaching are open-mindedness, patience and honesty [36, 37].

When looking at the organizational outcomes of the coaching program one need to discuss whether one should have one coach or several. Having one coach leads to the fact that the coach had knowledge and information about situations from several perspectives. When conflicts or problems were described by several coachees the coach in the study presented often had the possibility to make the coachee see the problem from different perspectives as other coachees had already talked about the problem. Other positive outcomes for the organisation resulting from the fact that there was one coach was the communication in the organisation was improved due to the fact that the coach could give tips and point at other parts of the organisation that worked with similar issues. Drawbacks of having one coach can be found in the fact that a group of active coaches might impact the organisation better since they would provide a multitude of different perspectives and experiences.

The complex nature of the problems addressed in the mentoring sessions meant that it was not a question of applying some research based theory and technique to solve the problem. Hence, potential solutions to the problems are found through a discussion and analysis of the problems at hand. The coachee and the coach contribute with their view of the situation, and the solutions are found through mutual understanding and discussions. 


\section{Implementation and Winding Up}

During the coaching meetings the problems experienced by the coachee should be the focus, and the coach helps the coachee to see and understand the problem from different perspectives as described by [35]. Handling of personal conflicts between the coachee and others in the organisation is one aspect that the coach needs to prepare for. Are these a natural part of a coaching session, or are they on the agenda somewhere else? If they are a part, how should they be treated?

When preparing each coaching session the coach should read through the diary, which includes things to remember. Such things might include reading material provided by the coachee or to look up relevant areas of research etc. Preferably this is done a few days in advance depending on the time that needs to be spent on for example copying or reading. It might be a good idea to have a rough meeting agenda when coming to the coaching session, as for example: 1 . What has happened since last time? 2. Problems that need to be discussed? 3. Anything more that needs to be discussed?

When winding up the usability coaching program it is a good idea to evaluate the learning experience. The method for the evaluation must be chosen to fit the situation at hand. The evaluation gives the coach input on what to improve in the coaching, and the coachee has the possibility to reflect on his/her learning experience during the mentoring sessions. However, it is not always possible to know what one has learned and in what way a coaching program has affected my sense making of my work and usability.

\section{Recommendations for Research and Practice}

Further research is needed to explore how the coachees made sense of the usability coaching and their experience of the impact on their actions. Here, recent theory building in research about coaching offers useful guidance considering what coachees learn in a coaching relationship, and offers a taxonomy of learning outcomes [19]. These categories include affective learning, which consist of changes in attitudes and motivation. Moreover, it would be interesting to further explore the ethical aspect of usability coaching, as usability coaching contains a number of ethical issues to be considered [38]. Another area of interest would be to evaluate the coaching together with the coachees. Our conclusion from this study is that usability coaching has the potential of being a powerful method in user-centred systems design and that organizations might gain from introducing this method. Our findings show that the usability coaching program made coachees more aware of their responsibility for usability, and in what ways usability related activities are part of their professional role.

\section{References}

1. Gulliksen, J., et al.: Key principles for user-centred systems design. Behaviour \& Information Technology 22(6), 397-409 (2003)

2. Gulliksen, J., et al.: User-Centred Systems Design as Organizational Change: A Longitudinal Action Research Project to Improve Usability and the Computerized Work Environment in a Public Authority. International Journal of Technology and Human Interaction 5(3), 13-53 (2009) 
3. Cajander, Å.: Values and Perspectives Affecting IT Systems Development and Usability Work, Department of Information Technology. Uppsala University, Uppsala (2006)

4. Cajander, Å., Gulliksen, J., Boivie, I.: Management perspectives on usability in a public authority: a case study. In: Proceedings of the 4th Nordic Conference on Human-Computer Interaction: Changing Roles, pp. 38-47 (2006)

5. Sandblad, B., et al.: Work environment and computer systems development. Behaviour and Information Technology - BIT 22(6), 375-387 (2003)

6. Greenbaum, J., Kyng, M. (eds.): Design at work: cooperative design of computer systems. ed. G. Joan and K. Morten, p. 294. Lawrence Erlbaum Associates, Inc., Mahwah (1992)

7. Kammersgaard, J.: Four Different Perspectives on Human Computer Interaction. In: Preece, J., Keller, L. (eds.) Human-Computer Interaction. Prentice-Hall, Cambridge (1990)

8. Gulliksen, J., et al.: Making a difference: a survey of the usability profession in Sweden. In: Proceedings of the Third Nordic Conference on Human-Computer Interaction, Tampere, Finland. ACM Press, New York (2004)

9. Boivie, I.: A Fine Balance: Addressing Usability and Users? In: Needs in the Development of IT Systems for the Workplace, p. 85. Acta Universitatis Upsaliensis, Uppsala (2005)

10. Orlikowski, W.J., Gash, D.C.: Technological frames: making sense of information technology in organizations. ACM Transactions on Information Systems (TOIS) 12(2), 174-207 (1994)

11. Rasmussen, L.B.: Action research-Scandinavian experiences. AI \& Society 18(1), 21-43 (2004)

12. McKay, J., Marschall, P.: The Dual Imperatives of Action Research. Information Technology \& People 14(1), 45-59 (2001)

13. Gulliksen, J., et al.: A longitudinal action research case on the introduction of usability and user-centred design into a public authority. The International Journal of Technology and Human Interaction, IJTHI (2009)

14. Cajander, Å.: Usability Mentoring - An Exploratory Study. In: INTERACT 2007. Rio de Janeiro, Brazil (2007)

15. Garvey, R., Stokes, P., Megginson, D.: Coaching and Mentoring: Theory and Practice. Sage Publilcations Ltd., Thousand Oaks (2009)

16. Mertz, N.T.: What's a Mentor, Anyway? Educational Administration Quarterly 40(4), 541 (2004)

17. Hartfield, B., Winograd, T., Bennett, J.: Learning HCI design: Mentoring project groups in a course on human-computer interaction. SIGCSE Bulletin (Association for Computing Machinery, Special Interest Group on Computer Science Education) 24(1), 246-251 (1992)

18. Allen, T.D., Eby, L.T.: Relationship Effectiveness for Mentors: Factors Associated with Learning and Quality. Journal of Management 29(4), 469 (2003)

19. Wanberg, C.R., Welsh, E.T., Hezlett, S.A.: Mentoring research: A review and dynamic process model. Research in Personnel and Human Resources Management 22, 39-124 (2003)

20. Aryee, S., Lo, S., Kang, I.L.: Antecedents of early career stage mentoring among Chinese employees. Journal of Organizational Behavior 20(5), 563-576 (1999)

21. Colarelli, S.M., Bishop, R.C.: Career commitment: Functions, correlates, and management. Group \& Organization Management 15(2), 158 (1990)

22. Kram, K.E.: Phases of the Mentor Relationship. The Academy of Management Journal 26(4), 608-625 (1983) 
23. Schön, D.A.: Educating the reflective practitioner (toward a new design for teaching and learning in the professions). Jossey-Bass, San Francisco (1987)

24. Rittel, H.W.J., Webber, M.M.: Dilemmas in a general theory of planning. Policy Sciences 4(2), 155-169 (1973)

25. Gullliksen, J., et al.: A longitudinal action research case on the introduction of usability and user-centred design into a public authority. The International Journal of Technology and Human Interaction, IJTHI (2009)

26. Kavathatzopoulos, I.: AvI-enkäten: Ett verktyg för att mäta användbarhet, stress och nytta av IT-stöd, It Department. Uppsala University (2007)

27. Johansson, N., et al.: A participatory Process Supporting Design of Future Work. In: Singh, S.K. (ed.) Ergonomics: An Introduction. Icfai University Press, India (2007)

28. Eriksson, E., Cajander, Å., Gulliksen, J.: Hello World! - System Developers Doing Field Studies. In: INTERACT 2009, Uppsala, Sweden (2009)

29. Posner, G.J., et al.: Accommodation of a scientific conception: Toward a theory of conceptual change. Science Education 66(2), 211-227 (1982)

30. Entwistle, N.: Conceptions of learning and the experience of understanding: thresholds, contextual influences, and knowledge objects. In: Re-framing the Conceptual Change Approach in Learning and Instruction, p. 123 (2007)

31. Meyer, J.H.F., Land, R.: Overcoming barriers to student understanding: Threshold concepts and troublesome knowledge. Routledge, New York (2006)

32. Entwistle, N.: Threshold Concepts and Transformative Ways of Thinking Within Research into Higher Education. In: Meyer, J.H.F., Land, R. (eds.) Threshold Concepts and Troublesome Knowledge: Linkages to Ways of Thinking and Practising within the Disciplines (2003)

33. Meyer, J.H.F., Land, R.: Threshold concepts and troublesome knowledge: Linkages to ways of thinking and practising within the disciplines. Occasional Report, 4 (2008)

34. Nørgaard, M.: Understanding Usability Work as a Human Activity. Københavns Universitet, Det Naturvidenskabelige Fakultet, Datalogisk Institut, Copenhaguen (2008)

35. Schön, D.: The Reflective Practitioner - How Professionals Think in Action. Ashgate Publishing, Aldershot (1983)

36. Allen, T.D., Poteet, M.L.: Developing effective mentoring relationships: Strategies from the mentor's viewpoint. Career Development Quarterly 48(1), 59-73 (1999)

37. Allen, T.D., Poteet, M.L., Burroughs, S.M.: The mentor's perspective: A qualitative inquiry and future research agenda. Journal of Vocational Behavior 51(1), 70-89 (1997)

38. McDonald, K.S., Hite, L.M.: Ethical Issues in Mentoring: The Role of HRD. Advances in Developing Human Resources 7(4), 569 (2005) 